\title{
FRET analyses of the U2AF complex localize the U2AF35/U2AF65 interaction in vivo and reveal a novel self-interaction of U2AF35
}

\author{
JANET CHUSAINOW, ${ }^{1,3}$ PAUl M. AJUH, ${ }^{1}$ LAURA TRINKLE-MULCAHY, ${ }^{1}$ JUDITH E. SLEEMAN, ${ }^{1,4}$ \\ JAN ELLENBERG, ${ }^{2}$ and ANGUS I. LAMOND ${ }^{1}$ \\ ${ }^{1}$ Wellcome Trust Biocentre, University of Dundee, Dundee DD1 5EH, United Kingdom \\ ${ }^{2}$ European Molecular Biology Laboratory, 69117 Heidelberg, Germany
}

\begin{abstract}
We have analyzed the interaction between the U2AF subunits U2AF35 and U2AF65 in vivo using fluorescence resonance energy transfer (FRET) microscopy. U2 snRNP Auxiliary Factor (U2AF) is an essential pre-mRNA splicing factor complex, comprising 35-kDa (U2AF35) and 65-kDa (U2AF65) subunits. U2AF65 interacts directly with the polypyrimidine tract and promotes binding of U2 snRNP to the pre-mRNA branchpoint, while U2AF35 associates with the conserved AG dinucleotide at the $3^{\prime}$ end of the intron and has multiple functions in the splicing process. Using two different approaches for measuring FRET, we have identified and spatially localized sites of direct interaction between U2AF35 and U2AF65 in vivo in live cell nuclei. While U2AF is thought to function as a heterodimeric complex, the FRET data have also revealed a novel U2AF35 selfinteraction in vivo, which is confirmed in vitro using biochemical assays. These results suggest that the stoichiometry of the U2AF complex may, at least in part, differ in vivo from the expected heterodimeric complex. The data show that FRET studies offer a valuable approach for probing interactions between pre-mRNA splicing factors in vivo.
\end{abstract}

Keywords: pre-mRNA splicing; U2AF; fluorescence microscopy; fluorescence resonance energy transfer (FRET)

\section{INTRODUCTION}

Pre-mRNA splicing is an essential step for the expression of eukaryotic genes by which the noncoding segments from precursor mRNA transcripts (pre-mRNAs) are specifically removed and the coding sequences joined to form mature mRNA. This process involves two sequential transesterification reactions and is catalyzed by the spliceosome, a dynamic, multicomponent complex. The spliceosome assembles in a stepwise manner on the pre-mRNA from five smaller RNAprotein subassemblies, called snRNPs (small nuclear ribonucleoprotein particles), and numerous non-snRNP protein splicing factors (for reviews, see Krämer 1996; Will and Luhrmann 1997; Staley and Guthrie 1998; Collins and Guthrie 2000). In two recent large-scale proteomic analyses of the

Present addresses: ${ }^{3}$ Bioprocessing Technology Institute, Singapore 138673; ${ }^{4}$ Division of Pathology and Neuroscience, Ninewells Hospital and Medical School, Dundee, DD1 9SY, United Kingdom.

Reprint requests to: Angus I. Lamond, Wellcome Trust Biocentre, University of Dundee, Dow Street, Dundee DD1 5EH, United Kingdom; e-mail: a.i.lamond@lifesci.dundee.ac.uk; fax: +44-1382-345695.

Article and publication are at http://www.rnajournal.org/cgi/doi/10.1261/ rna.7277705. human spliceosome $>300$ distinct proteins have been identified (Rappsilber et al. 2002; Zhou et al. 2002; for reviews, see Jurica and Moore 2003; Nilsen 2003).

Spliceosome assembly is directed by conserved premRNA sequences, including a short consensus sequence at each exon-intron junction and a branch point (BP) sequence followed by a polypyrimidine tract (Py tract), located within the intron adjacent to the $3^{\prime}$ splice site (for review, see Reed 2000). The BP contains an adenosine residue that forms a phosphodiester bond with the $5^{\prime}$ end of the intron during the first catalytic step of the splicing reaction (Ruskin et al. 1984). Spliceosome assembly is initiated by formation of the E complex, involving recognition of the $5^{\prime}$ splice site by U1 small nuclear RNP (Zhuang and Weiner 1986; Seraphin and Rosbash 1989; Siliciano and Guthrie 1988; Kohtz et al. 1994; Puig et al. 1999; Zhang and Rosbash 1999; Labourier et al. 2001; Zhang et al. 2001; Du and Rosbash 2002; Förch et al. 2002), binding of SF1/mBBP (splicing factor 1/branch-point binding protein) to the BP (Berglund et al. 1997; Rain et al. 1998), and U2 snRNP Auxiliary Factor (U2AF) to the Py tract and the $3^{\prime}$ splice site (Zamore et al. 1992; Reed 1996, 2000; Moore 2000). In humans, the essential splicing factor 
U2AF, composed of $35-\mathrm{kDa}$ (U2AF35) and $65-\mathrm{kDa}$ (U2AF65) subunits, is required for the recruitment of U2 snRNP to pre-mRNAs. U2AF65 binds specifically to the Py tract via its C-terminal RNA-binding domain, which consists of three RNA recognition motifs (RRMs) (Ruskin et al. 1988; Zamore et al. 1992; for review, see Krämer 1996). U2AF65 stabilizes the interaction of U2 snRNP with the BP by contacting the branch region through its N-terminal arginine- and serine-rich (RS) domain, promoting base pair interactions between U2 snRNA and the BP (Lee et al. 1993; Gaur et al. 1995; Valcarcel et al. 1996; Kent et al. 2003). In previous models it was suggested that U2AF65 function is based on interactions between RRM3 and SF1/ mBBP, or the U2 snRNP component SAP155, respectively (Berglund et al. 1997; Gozani et al. 1998). However, recent observations indicate that RRM3 is dispensable for both spliceosome assembly and splicing of certain introns in vitro but plays an essential role in vivo (Banerjee et al. 2003, 2004). Replacing SF1/mBBP, U2 snRNP associates with the BP through base pairing interactions between the $\mathrm{BP}$ sequence and U2 snRNA, while U2 snRNP proteins interact with upstream sequences in the pre-mRNA to form the A complex (Parker et al. 1987; Nelson and Green 1989; Wu and Manley 1989; Zhuang et al. 1989; Rosbash and Seraphin 1991; Gozani et al. 1998; Staley and Guthrie 1998; Burge et al. 1999; Reed 2000).

In addition to its well-characterized role in constitutive splicing, U2AF65 also plays an important role in regulated splicing (Black 2000; Smith and Valcarcel 2000; Graveley et al. 2001; Singh 2002). The U2AF35 binding domain of U2AF65 is located in the proline-rich fragment between the RS motif and RNA-binding region (Rudner et al. 1998; Kielkopf et al. 2001). The small subunit U2AF35 contacts the conserved AG dinucleotide at the $3^{\prime}$ splice site (Merendino et al. 1999; Wu et al. 1999; Zorio and Blumenthal 1999). Its primary structure comprises a central RRM that is flanked by two zinc fingers in the $\mathrm{N}$ terminus (Birney et al. 1993), and an RS domain and a glycine tract at the C terminus (Zhang et al. 1992; Kellenberger et al. 2002).

U2AF35 binds both U2AF65 and the pre-mRNA through its RRM domain. In addition to constitutive splicing, U2AF35 plays an important role in the splicing of both regulated introns and introns that have weak Py tracts (Guth et al. 1999). Several studies support a model in which splicing enhancer-bound SR proteins function by recruiting U2AF65 to weak Py tracts (Bouck et al. 1998; Wang et al. 1995; Zuo and Maniatis 1996; Graveley et al. 2001; for reviews, see Blencowe 2000 and Graveley 2000). In this model, recruitment requires interactions between the SR proteins and U2AF35. However, some studies are inconsistent with the $\mathrm{U} 2 \mathrm{AF}$ recruitment model (for reviews, see Blencowe 2000 and Graveley 2000). Recent experiments have demonstrated that, although the small U2AF subunit is necessary for efficient enhancer-dependent splicing, its RS domain is not required for this function
(Shepard et al. 2002). Both U2AF subunits have been shown to bind to intronic sequences of pre-mRNA only during the early steps of spliceosome assembly (Zamore et al. 1992; Merendino et al. 1999; Wu et al. 1999; Zorio and Blumenthal 1999) and to be replaced later by the U5 snRNP during B complex formation (Chiara et al. 1997).

To understand how the spliceosomal complex works, the structures, functions, and interactions of its components have to be determined. This includes the study of proteinprotein interactions between the various splicing factors. So far, most of the work on analyzing direct functional interactions between mammalian spliceosomal proteins has been based on in vitro biochemical methods or yeast twohybrid systems. Here, we have used imaging techniques for analyzing protein-protein interactions in the living cell to complement in vitro techniques. To advance our work on understanding functional interactions between essential protein splicing factors in vivo, we have analyzed the interaction between U2AF35 and U2AF65 using fluorescence resonance energy transfer (FRET) microscopy. FRET is a powerful technique that can provide insight into the spatial and temporal dynamics of protein-protein interactions in vivo (for reviews, see Day et al. 2001; Wouters et al. 2001; and Chen et al. 2003). Recently, Stanek and Neugebauer (2004) have investigated the subnuclear distribution of specific snRNP intermediates using a FRET assay. By analyzing distinct complexes containing the protein SART3, which is required for U4/U6 snRNP assembly, they have demonstrated that U4/U6 snRNP assembly occurs in Cajal bodies. To localize the transient complex formed between SART3 and the U4/U6 snRNP, SART3 and three U4/U6 snRNP-specific proteins were tagged with CFP or YFP, and FRET was measured by acceptor photobleaching.

The U2AF subunits U2AF35 and U2AF65 bind tightly to each other and form a stable complex, as previously demonstrated by copurification and codepletion experiments, as well as by cosedimentation on a glycerol gradient (Zamore and Green 1989; Zhang et al. 1992; Guth et al. 1999). Using two different microscopy systems and approaches for measuring FRET, we have localized sites of direct interaction between U2AF35 and U2AF65 in live cell nuclei. Interestingly, FRET also revealed a novel U2AF35 self-interaction in vivo, which was confirmed in vitro by using biochemical assays.

\section{RESULTS AND DISCUSSION}

\section{U2AF35 and U2AF65 colocalize in nuclear speckles with snRNP proteins and non-snRNP protein splicing factors}

For use in FRET analyses, EYFP (enhanced yellow fluorescent protein) and ECFP (enhanced cyan fluorescent protein) fusions of U2AF35 and U2AF65 were generated as described in Materials and Methods. To compare their subcellular localization with the localization patterns of 
the corresponding endogenous proteins, the fusion proteins were expressed in HeLa cells by transient transfection, and the cells were fixed in $3.7 \%$ paraformaldehyde, immunostained, and analyzed by fluorescence microscopy (Fig. 1). The transiently expressed EYFP-U2AF35 fusion protein concentrates in speckles with a diffuse nucleoplasmic fraction (Fig. 1A). Identical localization patterns were observed for EYFP-U2AF65, as well as for ECFP fusion proteins of U2AF35 and U2AF65 (data not shown; see Fig. 4). The merged image in Figure 1C demonstrates the colocalization of FP-tagged U2AF35 (Fig. 1A) with endogenous U2AF65 (Fig. 1B) in cells transiently expressing EYFP-U2AF35 and immunostained with anti-U2AF65. Rabbit polyclonal antipeptide antibodies against U2AF35 did not recognize U2AF35 when used for immunofluorescence cell staining. Cells transiently coexpressing FP-U2AF35 and FP-U2AF65 also showed colocalization in nuclear speckles, in both fixed and live cells (data not shown).

The localization patterns of U2AF35 and U2AF65 were investigated further in stable cell lines constitutively expressing either EYFP-U2AF35 (Fig. 1E) or EYFP-U2AF65 (Fig. 1I), respectively. As in transiently expressing cells, the fusion proteins are diffusely distributed in the nucleoplasm with additional concentration in nuclear speckles when constitutively expressed in HeLa cells. HeLa ${ }^{\text {EYFP-U2AF35 }}$ cells (Fig. 1E) were fixed and immunostained with anti-Y12 (Fig. 1F), which recognizes the Sm family of snRNP proteins. HeLa ${ }^{\text {EYFP-U2AF65 cells }}$ (Fig. 1I) were fixed and counterstained with an antibody

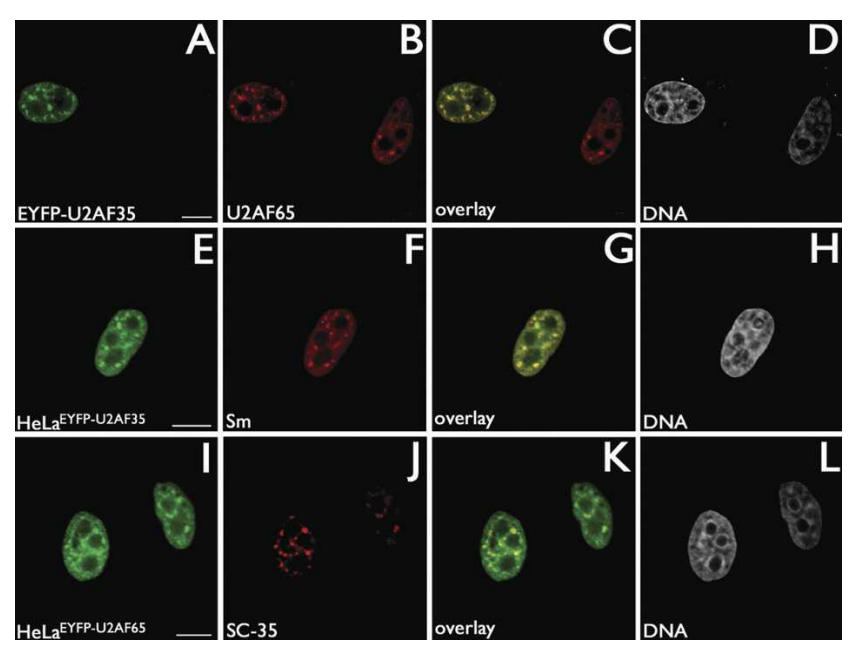

FIGURE 1. U2AF35 and U2AF65 colocalize in nuclear speckles with snRNP proteins and non-snRNP splicing factors. $(A-C) \mathrm{HeLa}$ cells transiently expressing EYFP-U2AF35 were counterstained with antiU2AF65. (overlay in $C$ ) EYFP-U2AF35 colocalizes with endogenous U2AF65. (E,F,overlay in $G) \mathrm{HeLa}^{\text {EYFP-U2AF35 }}$ cells were fixed and immunostained with anti-Y12, which recognizes the Sm family of snRNP proteins. (I,J,overlay in $K$ ) HeLa ${ }^{\text {EYFP-U2AF65 }}$ cells were fixed and immunostained with anti-SC-35, demonstrating colocalization with the non-snRNP protein splicing factor. $(E, I)$ Stable cell lines HeLa ${ }^{\text {EYFP-U2AF35 }}$ and HeLa ${ }^{\text {EYFP-U2AF65 }}$ show identical localization patterns as transiently expressing cells. $(D, H, L)$ Cells were DAPIstained to visualize the cell nucleus. Bars, $10 \mu \mathrm{m}$. specific for the non-snRNP protein splicing factor SC-35 (Fig. 1J). The merged images shown in Figure 1, G and K, respectively, demonstrate colocalization of EYFP-U2AF35 and EYFP-U2AF65 with both snRNP proteins and nonsnRNP protein splicing factors in nuclear speckles. The U2AF proteins have a larger nucleoplasmic fraction than SC35 (Fig. 1I,J). These observations are in agreement with previous studies (Gama-Carvalho et al. 1997, 2001).

\section{Characterization of stable cell lines HeLa $^{\text {EYFP-U2AF35 }}$ and HeLa ${ }^{\text {EYFP-U2AF65 }}$}

Stable cell lines constitutively expressing EYFP-U2AF35 $\left(\mathrm{HeLa}^{\mathrm{EYFP}-\mathrm{U} 2 \mathrm{AF} 35}\right)$ and EYFP-U2AF65 $\left(\mathrm{HeLa}^{\mathrm{EYFP}-\mathrm{U} 2 \mathrm{AF} 65}\right)$, respectively, were generated as described in Materials and Methods. In both cell lines, the FP-tagged protein is expressed in $>90 \%$ of cells and concentrates in speckles with a diffuse nucleoplasmic fraction (Fig. 1E,I). This is identical to the localization pattern observed with transiently expressing cells (Fig. 1A; data not shown), as well as by immunostaining endogenous protein in the parental HeLa cell line (shown for U2AF65 in Fig. 1B) (Gama-Carvalho et al. 1997).

To analyze the expression levels of the FP-tagged proteins in the stable cell lines, nuclear extracts ( $25 \mu \mathrm{g}$ total protein) from parental HeLa cells (Fig. 2A-C, lane 1) and stable cell lines $\mathrm{HeLa}^{\mathrm{EGFP}}$ (Fig. 2A-C, lane 2), $\mathrm{HeLa}^{\mathrm{EYFP}-\mathrm{U} 2 \mathrm{AF} 35}$ (Fig. 2A-C, lane 3), and HeLa ${ }^{\text {EYFP-U2AF65 }}$ (Fig. 2A-C, lane 4) were separated by SDS-PAGE and probed on Western blots with anti-U2AF35 (Fig. 2A), anti-U2AF65 (Fig. 2B), and anti-GFP (Fig. 2C) antibodies. The anti-peptide antibody raised against U2AF35 for these studies (see Materials and Methods) recognizes a single band of $\sim 30 \mathrm{kDa}$ for endogenous U2AF35 (Fig. 2A, lanes 1-4). Specifically for the HeLa ${ }^{\text {EYFP-U2AF35 }}$ cell line, the antibody additionally recognizes an EYFP-tagged U2AF35 band of $\sim 60 \mathrm{kDa}$ (Fig. 2A, lane 3). The monoclonal antibody MC3, directed against U2AF65 (Gama-Carvalho et al. 1997), recognizes a single band of $\sim 53 \mathrm{kDa}$ for endogenous U2AF65 (Fig. 2B, lanes 1-4) and, specifically in the HeLa ${ }^{\text {EYFP-U2AF65 }}$ cell line, an additional band of $\sim 83 \mathrm{kDa}$ for EYFP-U2AF65 (Fig. $2 \mathrm{~B}$, lane 4). Probing with an anti-GFP-antibody results in a single FP-positive band at $\sim 30 \mathrm{kDa}$ for EGFP in HeLa ${ }^{\mathrm{EGFP}}$ (Fig. 2C, lane 2), a $\sim 60 \mathrm{kDa}$ band for EYFP-U2AF35 in HeLa ${ }^{\text {EYFP-U2AF35 }}$ (Fig. 2C, lane 3), and a $\sim 83 \mathrm{kDa}$ signal for

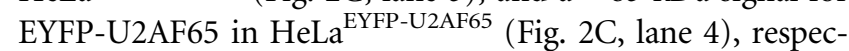
tively. As expected, no bands in the parental HeLa cell line are detected with anti-GFP (Fig. 2C, lane 1). HeLa cells constitutively expressing EYFP-U2AF35 and EYFPU2AF65, respectively, express full-length FP-protein at a similar or lower level to endogenous U2AF (Fig. 2A, lane 3; Fig. 2B, lane 4).

To investigate whether the expression of the FP-fusion proteins affected cell cycle progression, the growth properties of HeLa ${ }^{\text {EYFP-U2AF35 }}$ and HeLa ${ }^{\text {EYFP-U2AF65 }}$ cells were compared with those of both parental HeLa and HeLa ${ }^{\mathrm{EGFP}}$ cells. 

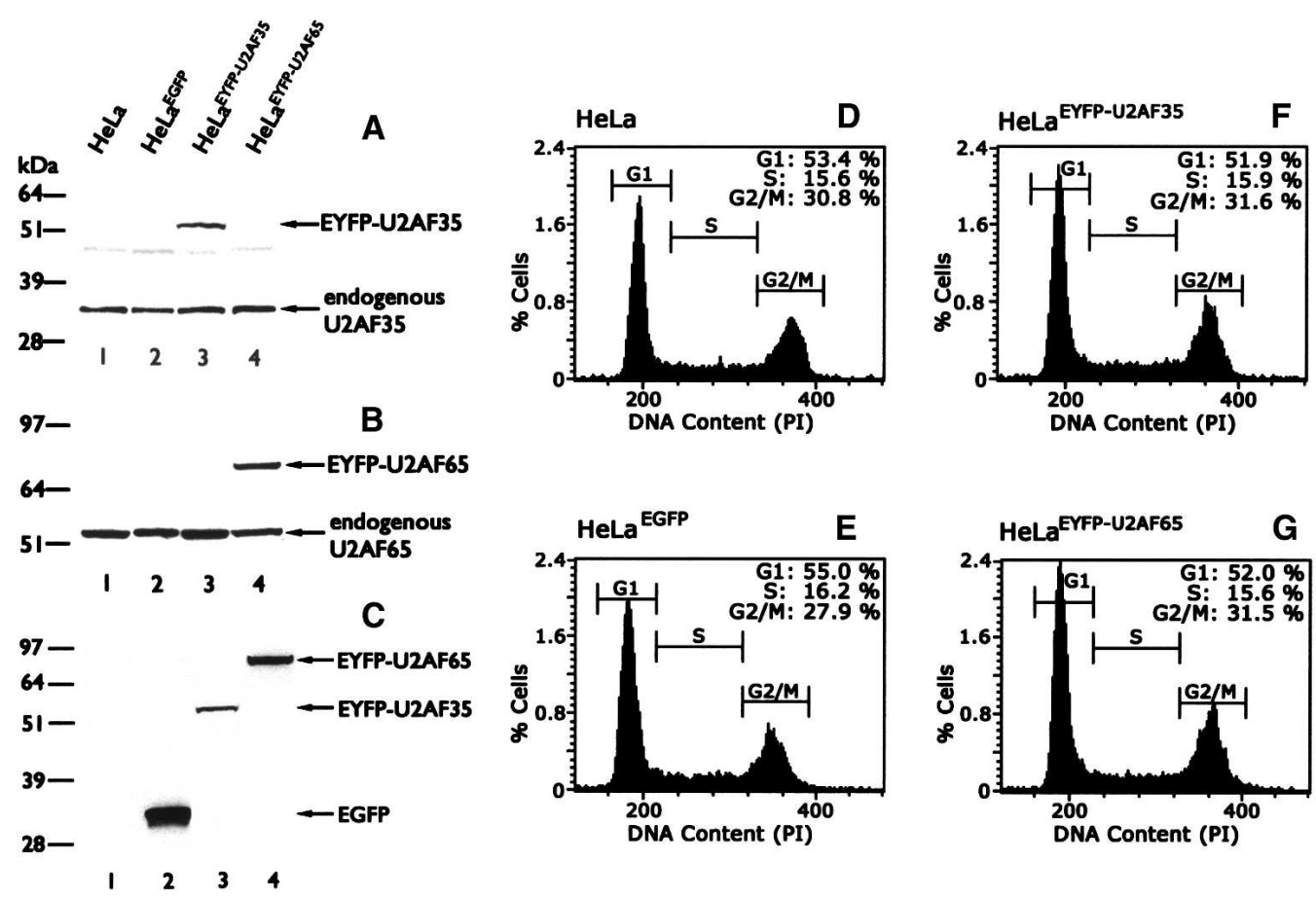

FIGURE 2. Characterization of stable cell lines HeLa ${ }^{\text {EYFP-U2AF35 }}$ and HeLa ${ }^{\text {EYFP-U2AF65 }}$. $(A, B)$ HeLa cells expressing EYFP-U2AF35 and EYFPU2AF65, respectively, express full-length FP-protein at a similar level to endogenous U2AF. Nuclear extracts (25 $\mu$ g total protein) from parental HeLa cells (lane 1) and stable cell lines HeLa ${ }^{\text {EGFP }}$ (lane 2), HeLa ${ }^{\text {EYFP-U2AF35 (lane 3), and HeLa }}{ }^{\text {EYFP-U2AF65 }}$ (lane 4) were probed on Western blots with anti-U2AF35 $(A)$, anti-U2AF65 $(B)$, and anti-GFP $(C)$. FACS analyses of synchronized cell populations stained with propidium iodide show similar distribution in cell cycle stages for parental HeLa $(D)$ and stable cell lines HeLa ${ }^{\mathrm{EGFP}}(E)$, HeLa ${ }^{\mathrm{EYFP}-\mathrm{U} 2 \mathrm{AF35}}(F)$, and HeLa ${ }^{\mathrm{EYFP}-\mathrm{U} 2 \mathrm{AF} 65}(G)$.

The growth rates of the respective cell lines are equivalent and, as confirmed by FACS analyses, the relative populations in the $\mathrm{G}_{1}, \mathrm{~S}$, and $\mathrm{G}_{2} / \mathrm{M}$ cell cycle stages are similar (Fig. 2D$\mathrm{G})$. We conclude that expression of the FP-fusion proteins in these cell lines does not prevent normal rates of either cell division or cell cycle progression.

\section{EYFP-U2AF35 and EYFP-U2AF65 bind pre-mRNA in vitro}

To confirm biochemically that the EYFP-fusion proteins of U2AF35 and U2AF65 are functional, we investigated whether the fusion proteins bind to pre-mRNA and whether nuclear extracts prepared from stable cell lines expressing the fusion proteins support pre-mRNA splicing in vitro. Nuclear extracts obtained from stable cell lines HeLa ${ }^{\mathrm{EYFP}-\mathrm{U} 2 \mathrm{AF} 35}$ and $\mathrm{HeLa}^{\text {EYFP-U2AF65 }}$ were analyzed in in vitro splicing assays (Fig. 3, lanes 4,5), and their splicing activities were compared with those of nuclear extracts from parental HeLa cells and $\mathrm{HeLa}^{\mathrm{EGFP}}$ stable cells (Fig. 3, lanes 2,3). For both $\mathrm{HeLa}{ }^{\text {EYFP-U2AF35 }}$ and HeLa ${ }^{\text {EYFP-U2AF65 }}$ cell lines, we observed equivalent pre-mRNA splicing efficiency as with control extracts. The stably expressed fusion proteins thus do not act as dominant-negative inhibitors of splicing, as may be expected if the fusion proteins were misfolded or otherwise inactive. To confirm that the FP-fusion proteins bind premRNA during spliceosome assembly, duplicates of the splicing reactions were immunoprecipitated using anti-GFP coupled Protein G-Sepharose. Following Proteinase K digestion, any coimmunoprecipitated RNA species were resolved on a denaturing RNA gel (Fig. 3, lanes 6-10). These data show that both stably expressed EYFP-U2AF35 (Fig. 3, lane 9) and EYFP-U2AF65 (Fig. 3, lane 10) bind pre-mRNA in in vitro splicing conditions but are not recovered with splicing intermediates or products. This observation is consistent with previous studies in which the U2AF subunits were found specifically in complexes formed during early steps of spliceosome assembly (Zamore et al. 1992; Merendino et al. 1999; Wu et al. 1999; Zorio and Blumenthal 1999). Stably expressed EGFP alone does not bind pre-mRNA in splicing conditions (Fig. 3, lane 8), serving as a negative control. Incubation of splicing reactions with beads without anti-GFP resulted in no signals on the RNA gel (Fig. 3, lanes 6,7), ruling out nonspecific binding of the pre-mRNA to the beads. Based upon the above combination of biochemical assays and fluorescence localization data, we conclude that the FRET analysis of the respective FP-tagged fusion proteins is likely to reflect interactions in vivo between the endogenous proteins.

\section{FRET microscopy analyses show that U2AF35 and U2AF65 interact directly in vivo}

In these experiments ECFP and EYFP serve as the donoracceptor pair for FRET. If donor (ECFP) and acceptor 


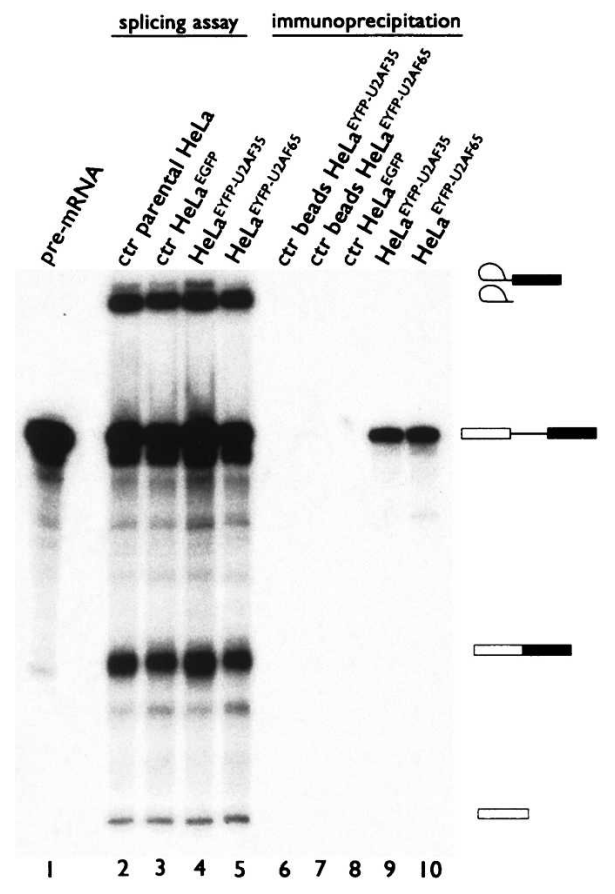

FIGURE 3. In vitro pre-mRNA splicing activity of stable cell lines HeLa ${ }^{\text {EYFP-U2AF35 }}$ and HeLa ${ }^{\text {EYFP-U2AF65, and binding of the FP-fusion }}$ proteins to pre-mRNA in splicing conditions. Nuclear extracts obtained from parental HeLa cells (lane 2) and stable cell lines HeLa ${ }^{\text {EGFP }}$ (lane 3), $\mathrm{HeLa}^{\mathrm{EYFP}-\mathrm{U} 2 \mathrm{AF} 35}$ (lane 4), and HeLa ${ }^{\mathrm{EYFP}-\mathrm{U} 2 \mathrm{AF} 65}$ (lane 5), respectively, were tested in in vitro splicing assays as described in Materials and Methods. Duplicates of the splicing reactions were subjected to immunoprecipitation using anti-GFP coupled Protein G-Sepharose. After washing the beads, immunoprecipitated proteins were digested, and coimmunoprecipitated RNA species were analyzed on a denaturing RNA gel (lanes 6-10). Both stably expressed EYFP-U2AF35 (lane 9) and EYFP-U2AF65 (lane 10) bind pre-mRNA in in vitro splicing conditions but are not associated with splicing intermediates or products. No RNA was coimmunoprecipitated with EGFP (lane 8), serving as negative control. Incubation of splicing reactions with beads without anti-GFP resulted in no signals on the RNA gel (lanes 6,7), ruling out nonspecific binding of pre-mRNA to the beads. Lane 1 shows $50 \%$ of the input pre-mRNA added to each splicing reaction.

(EYFP) are in close proximity $(<10 \mathrm{~nm})$ and in the appropriate relative orientation to each other, excitation of the donor molecule leads to transfer of energy to the acceptor. This energy transfer results in a decrease in emission from the donor and an increase in fluorescence at the emission wavelength of the acceptor. We measured FRET in two different ways: (1) by imaging sensitized emission and (2) by acceptor photobleaching. Both methods are based on measuring fluorescence intensities. Detecting sensitized emission is the technically more straightforward method for measuring FRET, but it is the more complex one to analyze. Although appropriate filter sets are used to isolate the specific signals from donor and acceptor, the detected FRET signal can be contaminated by spectral bleedthrough, which needs to be carefully corrected. Spectral bleed-through is contributed by both the donor emission that is detected in the acceptor (FRET) channel and by direct excitation of the acceptor fluorophore at the wavelength used to excite the donor. Therefore, donor-only and acceptor-only controls were included in the measurements. Nonetheless, variations in fluorophore concentration can complicate sensitized emission measurements of FRET by affecting the level of bleed-through, especially when studying transiently expressed fusion proteins. The advantage of acceptor photobleaching FRET microscopy is that only the donor fluorescence emission is measured, comparing the quenched with the unquenched donor emission after specific photobleaching of the acceptor fluorophore. In this approach, problems associated with spectral bleed-through and variations in fluorophore concentration are largely avoided.

\section{Direct protein-protein interaction between U2AF35 and U2AF65 detected by sensitized emission FRET microscopy}

A strong FRET signal was observed in live cells transiently coexpressing ECFP-U2AF65 and EYFP-U2AF35 (Fig. 4A-C), confirming the existence of a direct interaction between the two proteins in vivo. Figure 4C shows the FRET signal corrected for spectral bleed-through, FRETN, giving a diffuse nuclear
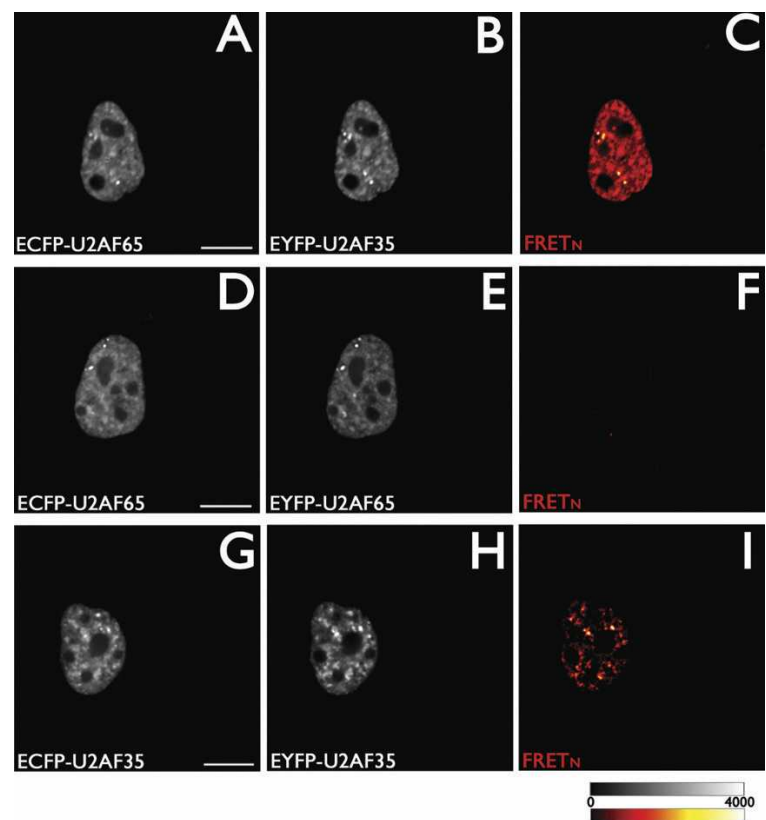

FIGURE 4. In vivo detection of direct protein-protein interactions between the U2AF subunits by sensitized emission FRET microscopy. Live HeLa cells transiently coexpressing ECFP-U2AF65 and EYFPU2AF35 $(A-C)$, ECFP-U2AF65 and EYFP-U2AF65 $(D-F)$, or ECFPU2AF35 and EYFP-U2AF35 $(G-I)$, respectively, were imaged on a wide-field fluorescence microscope as described under Materials and Methods. FRETN stands for spectral bleed-through corrected FRET signal. ECFP-U2AF65 $(A)$ and EYFP-U2AF35 $(B)$ show a strong FRET signal $(C)$; ECFP-U2AF35 $(G)$ and EYFP-U2AF35 $(H)$ show a slightly weaker but distinct FRET signal $(I)$. No FRET $(F)$ was observed in cells coexpressing ECFP-U2AF65 (D) and EYFP$\mathrm{U} 2 \mathrm{AF} 65(E)$, serving as negative control. All images are scaled to 0-4096 gray values (12-bit) and intensities colored as shown. FRETN images are illustrated in pseudo-colors. Bars, $10 \mu \mathrm{m}$. 
pattern with the strongest intensities at nuclear speckles. The same positive result was obtained when the fluorophores were exchanged, i.e., so that ECFP-U2AF35 was the donor and EYFP-U2AF65 the acceptor (data not shown). No detectable FRET was measured in cells coexpressing ECFP-U2AF65 and EYFP-U2AF65 (Fig. 4D-F), serving as a negative control.

As described below, we have detected a novel U2AF35 self-interaction in live cells coexpressing ECFP-U2AF35 and EYFP-U2AF35 (Fig. 4G-I).

\section{Direct protein-protein interaction between U2AF35 and U2AF65 detected by acceptor photobleaching FRET microscopy}

Following photobleaching of the acceptor (EYFP-U2AF35) in live HeLa cells coexpressing ECFP-U2AF65 and EYFP-U2AF35, a transient enhancement in the donor (ECFP-U2AF65) emission was observed (Fig. 5). This dequenching effect indicates an abolishment of FRET due to photobleaching of the acceptor fluorophore, and thus confirms that the two proteins interact directly in vivo. Images were acquired before (Fig. 5A-D) and after (Fig. 5E,F) photobleaching the acceptor (EYFP-U2AF35) with a single 150-msec stationary laser pulse. The post-bleach images, collected after $2 \mathrm{msec}$, clearly show the dequenching effect of the donor (Fig. 5E, arrow) as a result of bleaching the acceptor (Fig. 5F, arrow). Due to the rapid diffusion of unbleached acceptor into the bleach zone, dequenching of the donor was detectable only for a short time period of $\sim 1 \mathrm{sec}$. No detectable dequenching was observed in a nonbleached region (arrowhead) similar in intensity and structure to the bleached region. In Figure 5G, donor and acceptor mean signal intensities, monitored in the bleached and nonbleached regions, respectively, were plotted over time. Consistent with the results obtained by sensitized emission FRET microscopy, FRET between FPfusions of U2AF65 and U2AF35 remained when the fluorophores were switched. Figure $5 \mathrm{H}$ shows a diagram summarizing the FRET efficiencies obtained with the different protein pair combinations. There was little or no difference in FRET efficiencies detected from speckled regions compared with the diffuse nucleoplasmic regions, arguing that the interaction exists in both the speckles and the nucleoplasm. For the interaction between FP-U2AF35 and FP-U2AF65, FRET efficiencies of $16.4 \%$ and $21.0 \%$ were observed for the two combinations, respectively. A FRET efficiency of $2.6 \%$, observed for ECFPU2AF65 and EYFP-U2AF65, was considered as a negative result. A FRET efficiency $<5 \%$ is generally taken to be not significant.

\section{FRET microscopy reveals a novel self-interaction of U2AF35 in vivo}

Alongside FRET studies analyzing the direct interaction between U2AF35 and U2AF65 in vivo, we have also detected a novel U2AF35 self-interaction. A clear FRET signal was observed in live cells transiently coexpressing ECFP-U2AF35 and EYFP-U2AF35, both by detecting sensitized emission
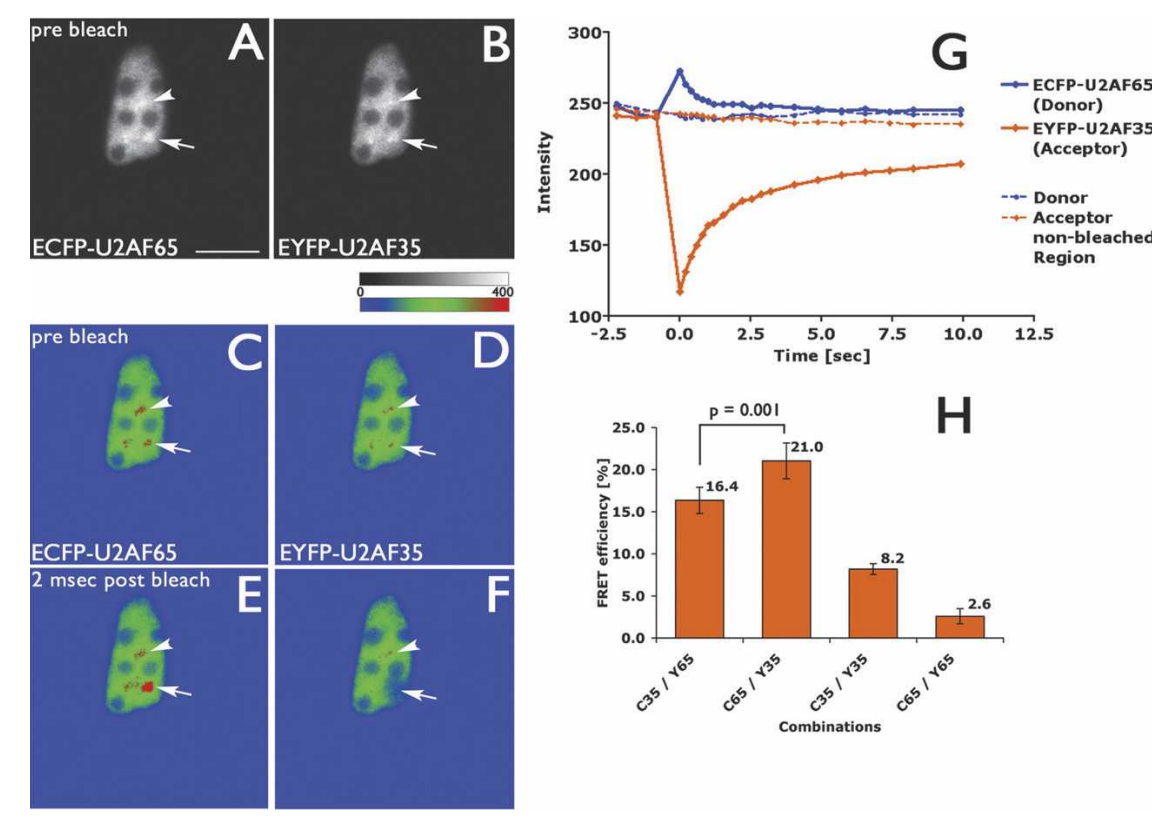

FIGURE 5. In vivo detection of direct protein-protein interactions between the U2AF subunits by acceptor photobleaching FRET microscopy. Live HeLa cells transiently coexpressing ECFP-U2AF65 $(A, C, E)$ and EYFP-U2AF35 $(B, D, F)$ were analyzed on a wide-field fluorescence microscope equipped with a quantifiable laser module as described under Materials and Methods. Images were acquired before $(A-D)$ and after $(E, F)$ photobleaching the acceptor (EYFP-U2AF35) with a single $150-\mathrm{msec}$ stationary laser pulse. Only the first post-bleach images of donor and acceptor collected after $2 \mathrm{msec}$ are displayed here. A nonbleached region (arrowhead) similar to the bleached region (arrow) was included in the data analysis for comparison. $(C-F)$ Images are illustrated in pseudo-colors. Bar, $10 \mu \mathrm{m}$. $(G)$ Donor and acceptor mean signal intensities monitored in the bleached and nonbleached regions were plotted over time. Photobleaching the acceptor fluorophore abolished FRET resulting in an enhancement in the donor emission because of dequenching. Because of a rapid recovery of the bleached acceptor, dequenching of the donor was detectable for a short time period of $\sim 1$ sec only. $(H)$ Acceptor photobleaching measurements were carried out for different protein pair combinations of ECFP-U2AF35 (C35), EYFP-U2AF35 (Y35), ECFP-U2AF65 (C65), and EYFP-U2AF65 (Y65), and the calculated FRET efficiencies are summarized in a diagram. For the interaction between FP-U2AF35 and FP-U2AF65 FRET, efficiencies of $16.4 \%$ and $21.0 \%$ were observed for the two combinations, respectively. A lower but distinct FRET efficiency of $8.2 \%$ was calculated for the U2AF35 self-interaction. A FRET efficiency of $2.6 \%$ observed for ECFP-U2AF65 and EYFP-U2AF65 was considered to be not significant. $\mathrm{n}=7$ cells for each measurement. 
(Fig. 4G-I) and by acceptor photobleaching FRET microscopy. For the U2AF35 self-interaction, the FRET efficiency was calculated to be $8.2 \%$ (Fig. $5 \mathrm{H}$ ). As observed for the interaction between U2AF35 and U2AF65, there was no apparent difference in FRET efficiencies detected from speckled regions as compared with the values obtained from diffuse nucleoplasmic regions.

\section{Interaction between U2AF35 and U2AF65 as well as the U2AF35 self-interaction persist in live cells when transcriptional activity is inhibited}

To investigate whether the protein-protein interaction between the U2AF subunits U2AF35 and U2AF65 and the U2AF35 self-interaction are dependent on splicing activity, live HeLa cells coexpressing the respective FP fusion proteins were treated with 5,6-dichloro-1-b-d-ribofuranosylbenzimidazole (DRB) to inhibit transcription, and hence splicing activity, before anayzing the protein-protein interactions by acceptor photobleaching FRET microscopy.

DRB treatment of live HeLa cells coexpressing ECFP-U2AF65 and EYFPU2AF35 resulted in a nuclear localization pattern typical for splicing protein factors in cells when transcription is inhibited; i.e., the pattern shows enlarged nuclear speckles, distinct from a dimmer, nonspeckled nucleoplasmic staining (Fig. 6). As in transcriptionally active cells, photobleaching the acceptor (EYFP-U2AF35) led to a transient enhancement in donor (ECFP-U2AF65) emission, confirming that the two proteins interact directly (Fig. 6). Images were acquired before (Fig. 6A-D) and after (Fig. 6E,F) photobleaching the acceptor (EYFP-U2AF35) with a single 150-msec stationary laser pulse. The post-bleach images, collected after 2 msec, clearly show the dequenching effect of the donor (Fig. 6E, arrow) as a result of bleaching the acceptor (Fig. $6 \mathrm{~F}$, arrow). No detectable dequenching was observed in a nonbleached region (arrowhead) similar in intensity and structure to the bleached region. In Figure $6 \mathrm{G}$, donor and acceptor mean signal intensities monitored in the bleached and nonbleached regions were plotted over time. FRET efficiencies obtained from acceptor photobleaching the enlarged speckles were compared with those obtained from the diffuse nucleoplasmic pool. The results are summarized in a diagram in Figure 6H. In cells coexpressing ECFP-U2AF65 and EYFP-U2AF35 where transcriptional activity was inhibited, positive FRET values were observed in both the enlarged speckles and the diffuse nucleoplasmic pool. The same observation was made when acceptor photobleaching FRET microscopy was carried out with cells coexpressing ECFP and EYFP fusion proteins of U2AF35 and inhibited in transcriptional activity (results summarized in Fig. $6 \mathrm{H}$ ). In contrast to cells coexpressing ECFP-U2AF65 and EYFP-U2AF35, where FRET efficiencies obtained from speckles and nucleoplasm had similar values, as statistically confirmed by applying the Student's t-test to the data (mean values not significantly different with $P=0.4, \mathrm{n}=3$ ), in cells coexpressing ECFP-U2AF35 and EYFPU2AF35, the FRET efficiencies measured at speckles were significantly higher than those measured in the nucleoplasmic pool (means significantly different with $P=0.005$, $\mathrm{n}=3$ ). In general, FRET efficiencies obtained from cells
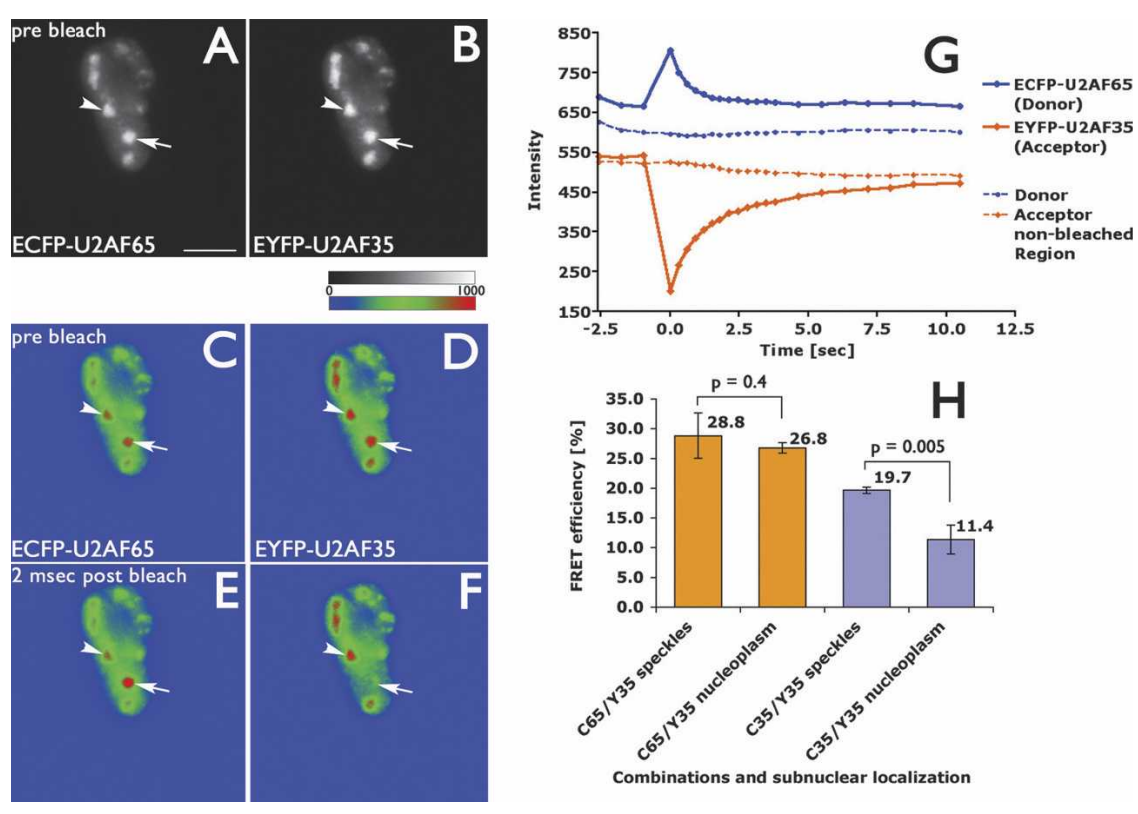

FIGURE 6. In vivo detection of direct protein-protein interactions between the U2AF subunits in live cells after blocking transcription. Live HeLa cells transiently coexpressing ECFPU2AF65 $(A, C, E)$ and EYFP-U2AF35 $(B, D, F)$ were treated with DRB as described in Material and Methods in order to block transcription and analyzed by acceptor photobleaching FRET microscopy. Images were acquired before $(A-D)$ and after $(E, F)$ photobleaching the acceptor (EYFP-U2AF35) with a single 150 -msec stationary laser pulse. $(E, F)$ The first post-bleach images of donor and acceptor collected after $2 \mathrm{msec}$. A nonbleached region (arrowhead) similar to the bleached region (arrow) was included in the data analysis for comparison. $(C-F)$ Images are illustrated in pseudo-colors. Bar, $10 \mu \mathrm{m}$. $(G)$ Donor and acceptor mean signal intensities monitored in the bleached and nonbleached regions were plotted over time. Photobleaching the acceptor fluorophore abolished FRET, resulting in an enhancement in the donor emission because of dequenching. Because of a rapid recovery of the bleached acceptor, dequenching of the donor was detectable for a short time period of $\sim 1$ sec only. Measurements were focused on nuclear speckles and diffused nucleoplasmic regions for comparison. $(H)$ FRET efficiencies were calculated and summarized in a diagram. Results, obtained from measurements with DRB-treated cells coexpressing ECFP-U2AF35 and EYFP-U2AF35, are also summarized in $H$. For the interaction between ECFP-U2AF65 and EYFP-U2AF35 in DRB-treated cells, FRET efficiencies of $29.7 \%$ in nuclear speckles and $26.3 \%$ in the diffused nucleoplasmic pool were observed. For the U2AF35 self-interaction in DRB-treated cells FRET efficiencies of $19.7 \%$ in nuclear speckles and $11.8 \%$ in the diffused nucleoplasmic pool were observed. $\mathrm{n}=7$ cells for each measurement. 
inhibited in transcriptional activity had higher values than those from nontreated cells. There are several possible reasons for the observed variations in FRET efficiencies. A possible explanation is that it results from the change in local concentration of FP-U2AF in speckles, which occurs when transcription is inhibited. The fluorophore concentration is a critical factor in intensity-based imaging as changes in donor and acceptor concentrations will affect the FRET measurement, in particular if the concentrations of the two fluorophores change to different extents. Furthermore, if the intensities are very low, an unfavorable signal-to-noise ratio can lead to an alteration in the FRET efficiency that is measured.

In summary, these data show that both the interaction between U2AF35 and U2AF65 and the U2AF35 selfinteraction exist independent of transcription levels in vivo and hence must occur in the presence of different levels of splicing activity. The observation that positive FRET values were obtained in both the enlarged speckles and the diffuse nucleoplasmic pool upon inhibition of transcription is consistent with U2AF complexes being preassembled before premRNA binding and recruitment into the spliceosome. Taken together, the above findings support the idea that nuclear speckles may play a role in storage and preassembly of spliceosome components (Spector 1993; Zhang et al. 1994).

\section{Biochemical assays confirm a U2AF35 self-interaction in vitro}

Having observed a novel self-interaction of U2AF35 in vivo, we next carried out biochemical assays to test whether this interaction could also be detected in vitro (Fig. 7). In a coimmunoprecipitation assay (Fig. 7A), nuclear extracts from parental HeLa cells, and HeLa ${ }^{\text {EGFP }}$ and HeLa ${ }^{\text {EYFP-U2AF35 }}$ stable cell lines, respectively, were incubated with Protein G-Sepharose coupled to anti-GFP antibodies. After washing the beads, immunoprecipitated proteins were separated by SDS-PAGE, blotted onto a nitrocellulose membrane, and probed with an anti-peptide antibody specific for U2AF35. Endogenous U2AF35 was coimmunoprecipitated from HeLa ${ }^{\text {EYFP-U2AF35 }}$ nuclear extracts (Fig. 7A, lane 5), resulting in a distinct protein band at $\sim 30 \mathrm{kDa}$, in addition to the fusion protein signal at $\sim 60 \mathrm{kDa}$. No endogenous U2AF35 was immunoprecipitated from parental HeLa (Fig. 7A, lane 3) or HeLa ${ }^{\mathrm{EGFP}}$ (Fig. 7A, lane 4) cells, respectively, serving as negative controls. Furthermore, a control reaction, where HeLa ${ }^{\text {EYFP-U2AF35 }}$ nuclear extract was incubated with beads without anti-GFP antibodies, resulted in no signals (Fig. 7A, lane 2), ruling out nonspecific binding of U2AF35 to the beads.

In a GST pull-down assay (Fig. 7B), in vitro translated, ${ }^{35} \mathrm{~S}$-radiolabeled U2AF35 was incubated with either recombinant protein GST-U2AF35 or GST-U2AF65, respectively, and captured on glutathione-Sepharose beads and washed, and the bound fractions were analyzed by SDS-PAGE and

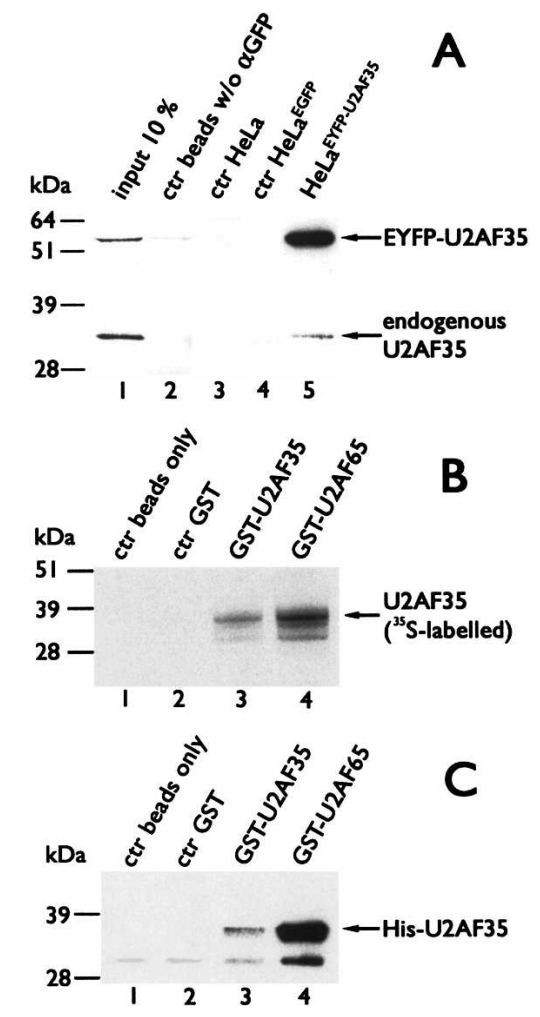

FIGURE 7. U2AF35 self-interaction analyzed in vitro. (A) Endogenous U2AF35 coimmunoprecipitates with EYFP-U2AF35 from HeLa ${ }^{\text {EYFP-U2AF35 }}$ cells. FP-tagged proteins were immunoprecipitated from nuclear extracts using anti-GFP antibodies, and the immunoprecipitates were probed on a Western blot for U2AF35. Endogenous U2AF35 was coimmunoprecipitated from HeLa ${ }^{\text {EYFP-U2AF35 nuclear }}$ extracts (lane 5) but not from parental HeLa (lane 3) or HeLa ${ }^{\mathrm{EGFP}}$ (lane 4) cells, respectively, serving as negative controls. A control reaction, where $\mathrm{HeLa}^{\mathrm{EYFP}-\mathrm{U} 2 \mathrm{AF} 35}$ nuclear extract was incubated with beads without anti-GFP, resulted in no signals (lane 2). Ten percent immunoprecipitation input amount of HeLa ${ }^{\text {YYFP-U2AF35 }}$ nuclear extract was separated in lane 1 for comparison. (B) In vitro translated U2AF35 copurifies with recombinant GST-U2AF35 protein. In vitro translated, ${ }^{35} \mathrm{~S}$-radiolabeled U2AF35 was incubated with recombinant protein GST-U2AF35 (lane 3) or GST-U2AF65 (lane 4), respectively, and captured on glutathione-Sepharose beads, and the bound fractions were analyzed by SDS-PAGE and detected by autoradiography. In vitro translated U2AF35 was co-purified with GST-U2AF35 (lane 3) and GST-U2AF65 (lane 4) but not with GST (lane 2), serving as a negative control. A control reaction, where in vitro translated U2AF35 was incubated with beads only, resulted in no signal (lane 1). (C) Recombinant His-tagged U2AF35 interacts with recombinant GSTU2AF35 protein. 6.His-U2AF35 was incubated with GST-U2AF35 (lane 3) or GST-U2AF65 (lane 4), respectively, captured on glutathione-Sepharose beads, and the bound fractions were probed on a Western blot for His-tagged protein. 6.His-U2AF35 was co-purified with GST-U2AF35 (lane 3) and GST-U2AF65 (lane 4) but not with GST (lane 2), serving as negative control. A control reaction, where His-tagged U2AF35 was incubated with beads only, resulted in no signals (lane 1).

detected by autoradiography. In vitro translated U2AF35 was copurified with GST-U2AF35 (Fig. 7B, lane 3) and GSTU2AF65 (Fig. 7B, lane 4), but not with GST alone (Fig. 7B, lane 2), serving as a negative control. A separate negative 
control reaction, where in vitro translated U2AF35 was incubated with beads only, resulted in no signals (lane 1), ruling out nonspecific binding of the in vitro translated protein to the beads.

Consistent results were obtained in a similar GST pulldown assay where recombinant His-tagged U2AF35 was incubated with either GST-U2AF35 or GST-U2AF65, respectively, and captured on glutathione-Sepharose beads and washed, and the bound fractions were analyzed by SDSPAGE, blotted onto a nitrocellulose membrane, and probed with S-protein HRP conjugate. 6.His-U2AF35 was copurified with GST-U2AF35 (Fig. 7C, lane 3) and GST-U2AF65 (Fig. 7C, lane 4), but not with GST alone (Fig. 7C, lane 2), serving as a negative control. A separate negative control reaction, where His-tagged U2AF35 was incubated with beads only, resulted in no signals (Fig. $7 \mathrm{C}$, lane 1). In summary, the biochemical assays confirm the existence of a U2AF35 selfinteraction in vitro, consistent with the in vivo FRET data.

While the cellular function of the U2AF35 self-interaction remains to be determined, the fact that it can be detected in vivo in live cells, as well as in vitro, indicates that it may be physiologically significant. The existence of a U2AF35 selfinteraction suggests that the stoichiometry of the U2AF complex may, at least in part, differ in vivo from the previously described heterodimeric complex. For example, both homodimeric and heterodimeric forms of U2AF35 may coexist and higher-order complexes could also form in vivo. In this regard it is notable that the RS domain of U2AF35, but not U2AF65, interacts with other splicing factors (Wu and Maniatis 1993). It will be interesting in the future to test whether other SR proteins can also form self-interactions similar to U2AF35.

Our data contrast with the results obtained in a previous study where no self-interaction of U2AF35 was observed in protein binding assays (Tronchere et al. 1997). This apparent discrepancy could be due to the different conditions used in the respective binding assays. For example, we observed that the U2AF35 self-interaction appears weaker than the U2AF65-U2AF35 interaction. Therefore, the self-interaction may not be detected if more stringent assay conditions are used, which nonetheless retain the U2AF65-U2AF35 interaction. The fact that this study has revealed a novel selfinteraction within the extensively studied U2AF complex emphasizes the potential that FRET microscopy techniques have to uncover new protein-protein interactions that may be overlooked by conventional methods.

\section{MATERIALS AND METHODS}

\section{Plasmid constructs}

FP-U2AF35 constructs were generated by EcoR1/BamH1 digestion and gel extraction from pEGFP-U2AF35 and ligation into pECFP-C1 and pEYFP-C1 (Clontech). pEGFP-U2AF35 was obtained by PCR amplification from pGEM-U2AF35 (gift from
Phillip D. Zamore, Univ. of Massachusetts Medical School) using the primers $5^{\prime}$-GCGGATCCTGGCTCAGAATCGCCCAGATCT-3' (forward) and 5'-GCGAATTCAATGGCGGAGTATCTGGCCTCC$3^{\prime}$ (reverse) and subcloned into pEG FP-C1 (Clontech) digested with EcoR1/BamH1. FP-U2AF65 constructs were gained by PCR amplification from pH $\beta$-U2AF65 (gift from Juan Valcarel, CRG, Barcelona, Spain) using the primers $5^{\prime}$-GCGGATCCTCTACCAGAAGTCCCG GCGGTG- $3^{\prime}$ (forward) and 5'-CGGAATTCCATGTCGGACTTC GACGAGTTC- $3^{\prime}$ (reverse) and ligated into pECFP-C1 and pEYFP$\mathrm{C} 1$ digested with EcoR1/BamH1. The constructs pGEX-U2AF35 and pET-U2AF35 were generated by PCR amplification from pEYFPU2AF35 using the primers 5 -GCGGATCCATGGCGGAGTATCTG GCCTC-3' (forward) and $5^{\prime}$-GAGAATTCGTCAGAATCGCCCAGA TCTTTC- $3^{\prime}$ (reverse) and ligated into pGEX-6P-3 (Amersham Biosciences) and pET-30a(+) (Novagen) digested with BamH1/EcoR1. pGEX-U2AF65 was gained by PCR amplification from pEYFPU2AF65 using the primers 5'-CTGGATCCATGTCGGACTTCGAC GAGTTC-3' (forward) and 5'-GAGAATTCTCTACCAGAAGTCC CGGCGGTG-3' (reverse) and subcloned into pGEX-6P-3 digested with BamH1/EcoR1. All generated plasmid constructs described above were confirmed by restriction analysis and sequencing.

\section{Peptide antibody production}

An anti-peptide antibody specific for U2AF35 was raised in rabbit using the peptide sequence YRNPQNSSQSADGL and was affinity-purified (Eurogentec). This sequence is located between the zinc finger region and the RRM domain at the $\mathrm{N}$ terminus of the protein and is a region that is unique to U2AF35 with little or no similarity to other proteins. The affinity-purified peptide-antibody was tested on HeLa nuclear extracts by immunobloting and on fixed HeLa cells by immunofluorescence microscopy.

\section{Cell culture, transfection assay, and generation of stable cell lines}

HeLa cells were cultured as monolayers in Dulbecco's modified Eagle medium supplemented with $10 \%$ fetal bovine serum and $100 \mathrm{U} / \mathrm{mL}$ penicillin-streptomycin (Invitrogen Life Technologies). For the expression and microscopic detection of fluorescent fusion proteins in vivo, cells were grown on glass coverslips and transfected with $1 \mu \mathrm{g}$ of the appropriate plasmid DNA using Effectene tranfection reagent (QIAGEN) according to the manufacturer's instructions. Cell fixation or live cell microscopy was carried out at 8-12 h post-transfection. Stable cell lines expressing EYFP-U2AF35 and EYFP-U2AF65, respectively, were generated using G418 selection of transiently transfected HeLa cells essentially as described previously (Sleeman et al. 2001).

\section{Cell fixation, immunofluorescence microscopy, and FACS analyses}

HeLa cells grown on glass coverslips were fixed for $5 \mathrm{~min}$ in freshly prepared $3.7 \%$ paraformaldehyde in $37^{\circ} \mathrm{C}$ PHEM buffer $(60 \mathrm{mM}$ PIPES, $25 \mathrm{mM}$ HEPES, $10 \mathrm{mM}$ EGTA, $2 \mathrm{mM} \mathrm{MgCl}_{2}$ [pH 6.9]). Permeabilizing was performed with $1 \%$ Triton X-100 in phosphate buffered saline (PBS) for $10 \mathrm{~min}$ at room temperature. After blocking the cells with $1 \%$ serum (goat) in PBS with $0.05 \%$ Tween 20 
(BDH) for $20 \mathrm{~min}$, they were incubated with primary antibody diluted in PBS/Tween 20 with $1 \%$ serum for $1 \mathrm{~h}$, washed, and incubated with the appropriate diluted secondary antibody for $45 \mathrm{~min}$. If required, cells were stained with DAPI $(0.3 \mu \mathrm{g} / \mathrm{mL}$, Sigma). After a final set of washes with PBS, cells were mounted in Vectashield medium (Vector Laboratories). Antibodies used were mouse mAb MC3, which is specific for U2AF65 (dilution 1:10) (Gama-Carvalho et al. 1997), mouse Y12 mAb anti-Sm (dilution 1:500) (Lerner et al. 1981; Pettersson et al. 1984), and mouse mAb directed against SC-35 (dilution 1:2000, Sigma-Aldrich) (Fu and Maniatis 1990). TRITC-conjugated goat anti-mouse IgG (dilution 1:500, Jackson ImmunoResearch Laboratories) was used as secondary antibody.

Three-dimensional images of fixed immunostained cells were recorded on a Zeiss Axiovert-DeltaVision Image Restoration Microscope (Applied Precision) as previously described (Platani et al. 2000) using a $100 \times$ numerical aperture (NA) 1.4 PlanApochromat objective and running SoftWorx (Applied Precision) imaging and deconvolution software.

For FACS analyses parental HeLa cells, HeLa ${ }^{\text {EGFP }}$ (TrinkleMulcahy et al. 2003), HeLa ${ }^{\text {EYFP-U2AF35, }}{ }^{\text {and HeLa }}{ }^{\text {EYFP-U2AF65 }}$ cells were harvested by trypsinization, washed with PBS, and fixed in $70 \%$ ethanol for $3 \mathrm{~h}$ at $4^{\circ} \mathrm{C}$. After staining the cells with $25 \mu \mathrm{g} / \mathrm{mL}$ propidium iodide in PBS containing $100 \mu \mathrm{g} / \mathrm{mL}$ RNase A, fluorescence was measured using a FACSort (Becton Dickinson), and data were analyzed using Cell Quest software (Becton Dickinson).

\section{FRET microscopy}

FRET measurements were implemented in two different ways: (1) by imaging sensitized emission and (2) by acceptor photobleaching. All measurements were carried out on live cells.

Sensitized emission FRET microscopy was performed basically as described previously (Trinkle-Mulcahy et al. 2001). HeLa cells grown on glass coverslips were cotransfected with an ECFP construct of U2AF35 or U2AF65, respectively, and an EYFP construct of U2AF35 or U2AF65 (Table 1). Eight to $12 \mathrm{~h}$ post-transfection, cells were mounted in HEPES buffered Phenol red-free medium (Invitrogen Life Technologies) in a closed, heated chamber (Bachofer) and imaged on the DeltaVision system (described above) using specific excitation and emission filters (Chroma) to resolve the ECFP and EYFP signals and running SoftWorx imaging software. To correct for spectral bleed-through and for uncontrolled variations in donoracceptor concentrations, a combination of donor, FRET, and acceptor filter sets was used to isolate and maximize three specific signals: donor fluorescence, acceptor fluorescence resulting from FRET, and the directly excited acceptor fluorescence, respectively. Filter sets used were as follows: excitation 436/10 $\mathrm{nm}$ and emission 470/30 $\mathrm{nm}$ for ECFP, excitation 500/20 nm and emission 535/30 nm for EYFP, and excitation $436 / 10 \mathrm{~nm}$ and emission 535/30 $\mathrm{nm}$ for FRET, and a dichroic filter JP4 (multiband beam splitter for ECFP and EYFP). FRET was measured by exciting cells at the ECFP (donor: excitation $433 \mathrm{~nm}$, emission 475 $\mathrm{nm}$ ) wavelength and detecting at the EYFP (acceptor: excitation $513 \mathrm{~nm}$, emission $527 \mathrm{~nm}$ ) emission wavelength. Three different specimen, containing just donor, just acceptor, and both donor and acceptor were examined with each of the three filter sets, and the resulting data were corrected for spectral bleed-through by using the following equation:

$$
\begin{aligned}
& \text { Net Energy Transfer } \\
& \text { FRETN }=\text { FRET signal }-\alpha(\text { donor signal })-\beta(\text { acceptor signal })
\end{aligned}
$$

For this equation, $\alpha$ and $\beta$ were determined by imaging the cells expressing each fusion protein on its own. In our system, $\sim 46 \%$ (SD $2 \%$ ) of the cyan signal and $24 \%$ (SD 1\%) of the yellow signal was detected with the FRET filter set. These numbers represent average values, each obtained from imaging 25 different cells.

To detect FRET by the method of acceptor photobleaching, cells were prepared the same way as described above for sensitized emission. Measurements were conducted on a DeltaVision Spectris Image Restoration Microscope (Applied Precision) fitted with a Quantifiable Laser Module (QLM) including a 20-mW 532-nm CW laser, suitable for photobleaching YFP without cobleaching CFP. Images were collected using an Olympus $60 \times$ NA 1.4 Plan-Apochromat lens, a Photometrics CoolSnap HQ cooled CCD camera and SoftWorx (Applied Precision) imaging software. The following specific CFP/YFP filter sets were used to resolve the ECFP and EYFP signals: excitation $436 / 10 \mathrm{~nm}$ and emission $480 / 40 \mathrm{~nm}$ for ECFP; excitation 525/20 $\mathrm{nm}$ and emission 580/70 $\mathrm{nm}$ for EYFP. The dichroics used were custom-built by Applied Precision and Chroma Technology. The set is modified from the normal CFP/YFP JP4 set such that the dichroic reflects and the emission filter rejects light at $532 \mathrm{~nm}$, allowing this wavelength to be used for selectively photobleaching YFP. After obtaining three pre-bleach images, a defined region of the cell nucleus was spot photobleached with a single 150-msec stationary pulse at $90 \%$ laser power. The first image was acquired 1-2 msec after the bleach event. For the first second, images were acquired approximately every $200 \mathrm{msec}$; for the

\begin{tabular}{|c|c|c|}
\hline Construct & Vector backbone & Purpose \\
\hline pGEM-U2AF35 & pGEM-3Zf $(+)$ & Starting material for cloning FP-U2AF35 constructs \\
\hline $\mathrm{pH}-\mathrm{U} 2 \mathrm{AF} 65$ & $\mathrm{pH}$ & Starting material for cloning FP-U2AF65 constructs \\
\hline $\begin{array}{l}\text { pECFP-U2AF35 } \\
\text { pECFP-U2AF65 }\end{array}$ & pECFP-C1 & $\begin{array}{l}\text { Expression of cyan fluorescent fusion proteins in } \\
\text { mammalian cells for fluorescence imaging, } \\
\text { including FRET studies }\end{array}$ \\
\hline $\begin{array}{l}\text { pEYFP-U2AF35 } \\
\text { pEYFP-U2AF65 }\end{array}$ & pEYFP-C1 & $\begin{array}{l}\text { Expression of yellow fluorescent fusion proteins } \\
\text { in mammalian cells for fluorescence imaging } \\
\text { and generation of stable cell lines }\end{array}$ \\
\hline $\begin{array}{l}\text { pGEX-U2AF35 } \\
\text { pGEX-U2AF65 }\end{array}$ & pGEX-6P-3 & $\begin{array}{l}\text { Expression of recombinant GST-tagged } \\
\text { proteins in bacteria }\end{array}$ \\
\hline pET-U2AF35 & pET-30a $(+)$ & $\begin{array}{l}\text { Expression of recombinant } 6 \cdot \text { His-tagged } \\
\text { protein in bacteria; in vitro } \\
\text { transcription/translation }\end{array}$ \\
\hline
\end{tabular}

TABLE 1. Plasmid constructs used and generated in this study 
following $1.7 \mathrm{sec}$, every $335 \mathrm{msec}$; and then at 830-msec intervals in the following $5 \mathrm{sec}$, after which images were acquired every 1.6 sec for the remainder of the experiment. A total of 20 images were acquired after the bleach event. Images of donor (ECFP) and acceptor (EYFP) were taken in separate subsequent measurements, bleaching exactly the same spot before collecting postbleach images. Obtained data were analyzed using the image analysis tools included in the SoftWorx software and the biostatistics program GraphPad Prism. In addition to the bleached region, a similar nonbleached nuclear region in the same cell was included in the data analysis as a control. A region of background fluorescence was defined outside the cell and subtracted from both the bleached and control regions. The data were normalized against the mean intensity of the whole image over time to account for any fluctuations and normal photobleaching that occur during image acquisition throughout the course of the experiment. FRET efficiency was calculated by the following formula:

$$
\begin{gathered}
\text { FRET Efficiency } \\
\mathrm{E}=\left(\mathrm{I}_{\mathrm{D}(\text { post })}-\mathrm{I}_{\mathrm{D}(\text { pre })}\right) / \mathrm{I}_{\mathrm{D}(\text { post })}
\end{gathered}
$$

where $\mathrm{I}_{\mathrm{D} \text { (pre) }}$ and $\mathrm{I}_{\mathrm{D} \text { (post) }}$ are donor intensity before and after photobleaching, respectively.

For inhibition of transcriptional activity, cells were treated for $2 \mathrm{~h}$ with $25 \mu \mathrm{g} / \mathrm{mL}$ DRB before carrying out FRET analyses by acceptor photobleaching.

\section{Preparation of nuclear extracts, immunoblotting, and immunoprecipitation}

Nuclear extracts were prepared from parental HeLa cells and stable cell lines as described previously (Ajuh et al. 2002). Twenty-five micrograms of nuclear protein was electrophoresed on a Novex $12 \%$ tris-glycine polyacrylamide gel using MOPS running buffer (Invitrogen) and transferred to Hybond-C Extra nitrocellulose membrane (Amersham Biosciences) for immunoblotting. Following blocking with $5 \%$ milk powder in PBS-Tween $(0.3 \%$ Tween 20 in PBS), the membranes were incubated with primary antibodies diluted in PBS-Tween containing 5\% milk powder for $1 \mathrm{~h}$. Primary antibodies used were rabbit peptide antibody anti-U2AF35 (described above; dilutuion 1:10,000 in PBS), mouse mAb MC3 directed against U2AF65 (dilution 1:500) (Gama-Carvalho et al. 1997), and mouse mAb anti-GFP (dilution 1:1000, Roche). After washing the membranes in PBS-Tween containing 5\% milk powder, they were incubated with the appropriate diluted secondary antibody for $45 \mathrm{~min}$. Secondary antibodies used were horseradish peroxidase (HRP)-conjugated goat anti-rabbit IgG and HRP-conjugated goat anti-mouse IgG (dilution 1:5000, Pierce). Detection was performed via chemiluminescence by using ECL reagents (Amersham Biosciences).

Nuclear extracts from parental HeLa cells, HeLa ${ }^{\text {EGFP }}$ (TrinkleMulcahy et al. 2003) and HeLa ${ }^{\text {EYFP-U2AF35 }}$ cells were precleared by incubation with $10 \mu \mathrm{L}$ Protein G-Sepharose (Amersham Biosciences) for $1 \mathrm{~h}$ on a shaking platform. Fifty microliters of precleared extract was incubated with $50 \mu \mathrm{L}$ Protein G-Sepharose coupled to $10 \mu \mathrm{g}$ anti-GFP mouse monoclonal antibody (Roche) in $400 \mu \mathrm{L}$ binding buffer (20 mM HEPES [pH 7.9], $0.1 \mathrm{M} \mathrm{KCl}, 0.2$ mM EDTA, $0.5 \mathrm{mM}$ PMSF, $0.5 \mathrm{mM}$ DTT) for $4 \mathrm{~h}$, rotating end over end at $4^{\circ} \mathrm{C}$. The beads were then washed four times with 250 $\mathrm{mM} \mathrm{NaCl}, 20 \mathrm{mM}$ Tris- $\mathrm{HCl}$ ( $\mathrm{pH} 7.5$ ), and $0.1 \%$ Triton X-100. The immunoprecipitated proteins and an equal amount of cleared input nuclear extract were separated on a $12 \%$ tris-glycine polyacrylamide gel, transferred to nitrocellulose membrane, and immunoblotted with anti-U2AF35 peptide antibody as described above.

\section{In vitro transcription/translation, expression, and purification of recombinant proteins and GST pull-down assays}

${ }^{35}$ S-labeled U2AF35 protein was generated from pET-U2AF35 plasmid DNA by in vitro transcription/translation using a TNT T7 rabbit reticulocyte lysate system (Promega) following the manufacturer's instructions.

Recombinant proteins GST-U2AF35 and GST-U2AF65 were expressed from pGEX-U2AF35 and pGEX-U2AF65, respectively, in Escherichia coli BL21 (DE3) (Novagen) and purified on glutathione-Sepharose (Amersham Biosciences) essentially as described previously (Ajuh et al. 2001) except that post induction with $0.04 \mathrm{mM}$ isopropyl-1-thio- $\beta \mathrm{D}$-galactopyranoside (IPTG), bacteria cultures were grown at room temperature for $1 \mathrm{~h}$ before lysing them. 6.His-U2AF35 recombinant protein was expressed from pET-U2AF35 in E. coli BL21 (DE3) pLysS (Novagen) and purified on nickel-nitrilotriacetic acid-agarose (QIAGEN) essentially as described previously (Ajuh et al. 2001) except that postinduction with $1 \mathrm{mM}$ IPTG, cells were grown at room temperature for $2 \mathrm{~h}$ prior lysis.

Approximately $0.15 \mathrm{nmol}$ of recombinant GST-fusion protein were incubated with equimolar amount of $6 \cdot \mathrm{His}-\mathrm{U} 2 \mathrm{AF} 35$ recombinant protein or $3 \mu \mathrm{L}$ of ${ }^{35} \mathrm{~S}$-labeled $\mathrm{U} 2 \mathrm{AF} 35$ in vitro translated protein, respectively, in $7 \mu \mathrm{L}$ binding buffer $(350 \mathrm{mM} \mathrm{NaCl}, 20 \mathrm{mM}$ Tris- $\mathrm{HCl}$ [pH 7.5], 0.1\% Triton X-100, $1 \mathrm{mg} / \mathrm{mL}$ bovine serum albumin) and incubated at room temperature for $15 \mathrm{~min}$. The reaction was diluted in $500 \mu \mathrm{L}$ binding buffer and then transferred to a tube containing $30 \mu \mathrm{L}$ glutathione-Sepharose. The binding reaction was incubated for $1 \mathrm{~h}$ at $4^{\circ} \mathrm{C}$ on a shaking platform. The beads were washed four times with $350 \mathrm{mM} \mathrm{NaCl}, 20 \mathrm{mM}$ Tris- $\mathrm{HCl}$ (pH 7.5), and 0.1\% Triton X-100. Bound proteins were separated on a $12 \%$ tris-glycine polyacrylamide gel. $6 \cdot \mathrm{His}-\mathrm{U} 2 \mathrm{AF} 35$ protein was transferred to nitrocellulose membrane and detected by using S-protein HRP conjugate (Novagen) following the manufacturer's instructions. To detect ${ }^{35} \mathrm{~S}$ labeled U2AF35, gel was fixed in 50\% methanol and 10\% acetic acid for $30 \mathrm{~min}$. Fixed gel was soaked in Amplify fluorographic reagent (Amersham Biosciences) with agitation on a platform shaker for $30 \mathrm{~min}$ and then dried. Detection was performed by autoradiography.

\section{In vitro pre-mRNA splicing assay and immunoprecipitation of the splicing reaction}

Splicing assays were performed using uniformly labeled, capped pre-mRNAs incubated with nuclear extracts using the in vitro splicing conditions described previously (Lamond et al. 1987). Adenovirus major late precursor (adeno pre-mRNA) was transcribed from Sau3A-digested plasmid pBSAd1 (Konarska and Sharp 1987). Splicing products were separated on a $10 \%$ polyacrylamide/8 $\mathrm{M}$ urea denaturing gel using Tris-borate/EDTA electrophoresis buffer and detected by autoradiography. 
For each immunoprecipitation reaction, $50 \mu \mathrm{L}$ Protein GSepharose coupled to $10 \mu \mathrm{g}$ anti-GFP monoclonal antibody (Roche) was preblocked to minimize nonspecific binding. This was done by incubating the beads in $1 \mathrm{~mL}$ blocking buffer $(20 \mathrm{mM}$ HEPES [pH 7.9], $0.3 \mathrm{M} \mathrm{KCl}, 0.01 \%$ Nonidet P40, $50 \mu \mathrm{g} / \mathrm{mL}$ glycogen, $50 \mu \mathrm{g} / \mathrm{mL}$ tRNA, $1 \mathrm{mg} / \mathrm{mL}$ BSA) for $30 \mathrm{~min}$ rotating at $4^{\circ} \mathrm{C}$. Subsequently, the beads were washed four times with binding buffer (20 mM HEPES [pH 7.9], $0.15 \mathrm{M} \mathrm{KCl}, 0.1 \%$ Nonidet P40, $1 \mathrm{mg} / \mathrm{mL}$ BSA). Splicing reactions prepared with nuclear extracts from parental HeLa ${ }^{\mathrm{EGFP}}$ (Trinkle-Mulcahy et al. 2003), HeLa ${ }^{\text {EYFP-U2AF35, and HeLa }}{ }^{\text {EYFP-U2AF65 }}$ cells, respectively, were incubated with preblocked beads in $400 \mu \mathrm{L}$ binding buffer for $3 \mathrm{~h}$ rotating at $4^{\circ} \mathrm{C}$, followed by four washes with $150 \mathrm{mM}$ $\mathrm{NaCl}$ and $20 \mathrm{mM}$ Tris- $\mathrm{HCl}(\mathrm{pH}$ 7.5). In order to elute and digest immunoprecipitated protein and extract coimmunoprecipitated RNA, the beads were incubated in $90 \mu \mathrm{L}$ elution buffer (2\% SDS, $20 \mathrm{mM}$ Tris-HCl [pH 7.5], $20 \mathrm{mM}$ DTT), containing $300 \mu \mathrm{g}$ Proteinase $\mathrm{K}$ and $12 \mu \mathrm{g}$ glycogen, for $45 \mathrm{~min}$ at $65^{\circ} \mathrm{C}$. The RNA was ethanol-precipitated, resolved on a denaturing RNA gel as described above, and visualized by autoradiography.

\section{ACKNOWLEDGMENTS}

We thank Phillip D. Zamore for the construct pGEM-U2AF35 and Juan Valcarcel for the $\mathrm{pH} \beta-\mathrm{U} 2 \mathrm{AF} 65$ plasmid. We are also grateful to Jason R. Swedlow for technical help with the acceptor photobleaching measurements. Thanks to all members of the Lamond laboratory and the Ellenberg group for support. A.I.L. is a Wellcome Trust Principal Research Fellow. J.C. was supported by a Biotechnology and Biological Sciences Research Council fellowship.

Received December 20, 2004; accepted April 29, 2005.

\section{REFERENCES}

Ajuh, P., Sleeman, J., Chusainow, J., and Lamond, A.I. 2001. A direct interaction between the carboxyl-terminal region of CDC5L and the WD40 domain of PLRG1 is essential for pre-mRNA splicing. J. Biol. Chem. 276: 42370-42381.

Ajuh, P., Chusainow, J., Ryder, U., and Lamond, A.I. 2002. A novel function for human factor $\mathrm{C} 1$ (HCF-1), a host protein required for herpes simplex virus infection, in pre-mRNA splicing. EMBO J. 21: 6590-6602.

Banerjee, H., Rahn, A., Davis, W., and Singh, R. 2003. Sex lethal and U2 small nuclear ribonucleoprotein auxiliary factor (U2AF65) recognize polypyrimidine tracts using multiple modes of binding. RNA 9: 88-99.

Banerjee, H., Rahn, A., Gawande, B., Guth, S., Valcarcel, J., and Singh, R. 2004. The conserved RNA recognition motif 3 of U2 snRNA auxiliary factor (U2AF 65) is essential in vivo but dispensable for activity in vitro. RNA 10: $240-253$.

Berglund, J.A., Chua, K., Abovich, N., Reed, R., and Rosbash, M. 1997. The splicing factor BBP interacts specifically with the premRNA branchpoint sequence UACUAAC. Cell 89: 781-787.

Birney, E., Kumar, S., and Krainer, A.R. 1993. Analysis of the RNArecognition motif and RS and RGG domains: Conservation in metazoan pre-mRNA splicing factors. Nucleic Acids Res. 21: 5803-5816.

Black, D.L. 2000. Protein diversity from alternative splicing: A challenge for bioinformatics and post-genome biology. Cell 103: 367370 .
Blencowe, B.J. 2000. Exonic splicing enhancers: Mechanism of action, diversity and role in human genetic diseases. Trends Biochem. Sci. 25: $106-110$.

Bouck, J., Fu, X.D., Skalka, A.M., and Katz, R.A. 1998. Role of the constitutive splicing factors U2AF65 and SAP49 in suboptimal RNA splicing of novel retroviral mutants. J. Biol. Chem. 273: 15169-15176.

Burge, C.B., Tuschl, T., and Sharp, P.A. 1999. Splicing of precursors to mRNAs by the spliceosomes. In The RNA world (eds. R.F. Gesteland et al.), pp. 525-560. Cold Spring Harbor Laboratory Press, Cold Spring Harbor, NY.

Chen, Y., Mills, J.D., and Periasamy, A. 2003. Protein localization in living cells and tissues using FRET and FLIM. Differentiation 71: 528-541.

Chiara, M.D., Palandjian, L., Feld Kramer, R., and Reed, R. 1997. Evidence that U5 snRNP recognizes the $3^{\prime}$ splice site for catalytic step II in mammals. EMBO J. 16: 4746-4759.

Collins, C.A. and Guthrie, C. 2000. The question remains: Is the spliceosome a ribozyme? Nat. Struct. Biol. 7: 850-854.

Day, R.N., Periasamy, A., and Schaufele, F. 2001. Fluorescence resonance energy transfer microscopy of localized protein interactions in the living cell nucleus. Methods 25: 4-18.

$\mathrm{Du}, \mathrm{H}$. and Rosbash, M. 2002. The U1 snRNP protein U1C recognizes the $5^{\prime}$ splice site in the absence of base pairing. Nature 419: 86-90.

Förch, P., Puig, O., Martinez, C., Seraphin, B., and Valcarcel, J. 2002. The splicing regulator TIA-1 interacts with U1-C to promote U1 snRNP recruitment to $5^{\prime}$ splice sites. EMBO J. 21: 6882-6892.

$\mathrm{Fu}$, X.D. and Maniatis, T. 1990. Factor required for mammalian spliceosome assembly is localized to discrete regions in the nucleus. Nature 343: 437-441.

Gama-Carvalho, M., Krauss, R.D., Chiang, L., Valcarcel, J., Green, M.R., and Carmo-Fonseca, M. 1997. Targeting of U2AF65 to sites of active splicing in the nucleus. J. Cell Biol. 137: 975-987.

Gama-Carvalho, M., Carvalho, M.P., Kehlenbach, A., Valcarcel, J., and Carmo-Fonseca, M. 2001. Nucleocytoplasmic shuttling of heterodimeric splicing factor U2AF. J. Biol. Chem. 276: 1310413112.

Gaur, R.K., Valcarcel, J., and Green, M.R. 1995. Sequential recognition of the pre-mRNA branch point by U2AF65 and a novel spliceosome-associated 28-kDa protein. RNA 1: 407-417.

Gozani, O., Potashkin, J., and Reed, R. 1998. A potential role for U2AF-SAP 155 interactions in recruiting U2 snRNP to the branch site. Mol. Cell. Biol. 18: 4752-4760.

Graveley, B.R. 2000. Sorting out the complexity of SR protein functions. RNA 6: 1197-1211.

Graveley, B.R., Hertel, K.J., and Maniatis, T. 2001. The role of U2AF35 and U2AF65 in enhancer-dependent splicing. RNA 7: 806-818.

Guth, S., Martinez, C., Gaur, R.K., and Valcarcel, J. 1999. Evidence for substrate-specific requirement of the splicing factor $\operatorname{U} 2 \mathrm{AF}(35)$ and for its function after polypyrimidine tract recognition by U2AF(65). Mol. Cell. Biol. 19: 8263-8271.

Jurica, M.S. and Moore, M.J. 2003. Pre-mRNA splicing: Awash in a sea of proteins. Mol. Cell 12: 5-14.

Kellenberger, E., Stier, G., and Sattler, M. 2002. Induced folding of the U2AF35 RRM upon binding to U2AF65. FEBS Lett. 528: 171-176.

Kent, O.A., Reayi, A., Foong, L., Chilibeck, K.A., and MacMillan, A.M. 2003. Structuring of the $3^{\prime}$ splice site by U2AF65. J. Biol. Chem. 278: 50572-50577.

Kielkopf, C.L., Rodionova, N.A., Green, M.R., and Burley, S.K. 2001. A novel peptide recognition mode revealed by the X-ray structure of a core U2AF35/U2AF65 heterodimer. Cell 106: 595-605.

Kohtz, J.D., Jamison, S.F., Will, C.L., Zuo, P., Luhrmann, R., GarciaBlanco, M.A., and Manley, J.L. 1994. Protein-protein interactions and $5^{\prime}$-splice-site recognition in mammalian mRNA precursors. Nature 368: 119-124. 
Konarska, M.M. and Sharp, P.A. 1987. Interactions between small nuclear ribonucleoprotein particles in formation of spliceosomes. Cell 49: 763-774.

Krämer, A. 1996. The structure and function of proteins involved in mammalian pre-mRNA splicing. Annu. Rev. Biochem. 65: 367-409.

Labourier, E., Adams, M.D., and Rio, D.C. 2001. Modulation of P-element pre-mRNA splicing by a direct interaction between PSI and U1 snRNP 70K protein. Mol. Cell 8: 363-373.

Lamond, A.I., Konarska, M.M., and Sharp, P.A. 1987. A mutational analysis of spliceosome assembly: Evidence for splice site collaboration during spliceosome formation. Genes \& Dev. 1: 532-543.

Lee, C.G., Zamore, P.D., Green, M.R., and Hurwitz, J. 1993. RNA annealing activity is intrinsically associated with U2AF. J. Biol. Chem. 268: 13472-13478.

Lerner, E.A., Lerner, M.R., Janeway Jr., C.A., and Steitz, J.A. 1981. Monoclonal antibodies to nucleic acid-containing cellular constituents: Probes for molecular biology and autoimmune disease. Proc. Natl. Acad. Sci. 78: 2737-2741.

Merendino, L., Guth, S., Bilbao, D., Martinez, C., and Valcarcel, J. 1999. Inhibition of msl-2 splicing by Sex-lethal reveals interaction between U2AF35 and the $3^{\prime}$ splice site AG. Nature 402: 838-841.

Moore, M.J. 2000. Intron recognition comes of AGe. Nat. Struct. Biol. 7: $14-16$.

Nelson, K.K. and Green, M.R. 1989. Mammalian U2 snRNP has a sequence-specific RNA-binding activity. Genes \& Dev. 3: 1562 1571.

Nilsen, T.W. 2003. The spliceosome: The most complex macromolecular machine in the cell? Bioessays 25: 1147-1149.

Parker, R., Siliciano, P.G., and Guthrie, C. 1987. Recognition of the TACTAAC box during mRNA splicing in yeast involves base pairing to the U2-like snRNA. Cell 49: 229-239.

Pettersson, I., Hinterberger, M., Mimori, T., Gottlieb, E., and Steitz, J.A. 1984. The structure of mammalian small nuclear ribonucleoproteins: Identification of multiple protein components reactive with anti-(U1) ribonucleoprotein and anti-Sm autoantibodies. J. Biol. Chem. 259: 5907-5914.

Platani, M., Goldberg, I., Swedlow, J.R., and Lamond, A.I. 2000. In vivo analysis of Cajal body movement, separation, and joining in live human cells. J. Cell. Biol. 151: 1561-1574.

Puig, O., Gottschalk, A., Fabrizio, P., and Seraphin, B. 1999. Interaction of the U1 snRNP with nonconserved intronic sequences affects $5^{\prime}$ splice site selection. Genes \& Dev. 13: 569-580.

Rain, J.C., Rafi, Z., Rhani, Z., Legrain, P., and Kramer, A. 1998. Conservation of functional domains involved in RNA binding and protein-protein interactions in human and Saccharomyces cerevisiae pre-mRNA splicing factor SF1. RNA 4: 551565.

Rappsilber, J., Ryder, U., Lamond, A.I., and Mann, M. 2002. Largescale proteomic analysis of the human spliceosome. Genome Res. 12: 1231-1245.

Reed, R. 1996. Initial splice-site recognition and pairing during premRNA splicing. Curr. Opin. Genet. Dev. 6: 215-220.

. 2000. Mechanisms of fidelity in pre-mRNA splicing. Curr. Opin. Cell Biol. 12: 340-345.

Rosbash, M. and Seraphin, B. 1991. Who's on first? The U1 snRNP-5' splice site interaction and splicing. Trends Biochem. Sci. 16: 187190.

Rudner, D.Z., Kanaar, R., Breger, K.S., and Rio, D.C. 1998. Interaction between subunits of heterodimeric splicing factor U2AF is essential in vivo. Mol. Cell. Biol. 18: 1765-1773.

Ruskin, B., Krainer, A.R., Maniatis, T., and Green, M.R. 1984. Excision of an intact intron as a novel lariat structure during premRNA splicing in vitro. Cell 38: 317-331.

Ruskin, B., Zamore, P.D., and Green, M.R. 1988. A factor, U2AF, is required for U2 snRNP binding and splicing complex assembly. Cell 52: 207-219.
Seraphin, B. and Rosbash, M. 1989. Identification of functional U1 snRNA-pre-mRNA complexes committed to spliceosome assembly and splicing. Cell 59: 349-358.

Shepard, J., Reick, M., Olson, S., and Graveley, B.R. 2002. Characterization of $\mathrm{U} 2 \mathrm{AF}(26)$, a splicing factor related to $\mathrm{U} 2 \mathrm{AF}(35)$. Mol. Cell. Biol. 22: 221-230.

Siliciano, P.G. and Guthrie, C. 1988. 5' splice site selection in yeast: Genetic alterations in base-pairing with $\mathrm{U} 1$ reveal additional requirements. Genes \& Dev. 2: 1258-1267.

Singh, R. 2002. RNA-protein interactions that regulate pre-mRNA splicing. Gene Expr. 10: 79-92.

Sleeman, J.E., Ajuh, P., and Lamond, A.I. 2001. snRNP protein expression enhances the formation of Cajal bodies containing p80-coilin and SMN. J. Cell Sci. 114: 4407-4419.

Smith, C.W. and Valcarcel, J. 2000. Alternative pre-mRNA splicing: The logic of combinatorial control. Trends Biochem. Sci. 25: 381-388.

Spector, D.L. 1993. Nuclear organization of pre-mRNA processing. Curr. Opin. Cell Biol. 5: 442-447.

Staley, J.P. and Guthrie, C. 1998. Mechanical devices of the spliceosome: Motors, clocks, springs, and things. Cell 92: 315-326.

Stanek, D. and Neugebauer, K.M. 2004. Detection of snRNP assembly intermediates in Cajal bodies by fluorescence resonance energy transfer. J. Cell Biol. 166: 1015-1025.

Trinkle-Mulcahy, L., Sleeman, J.E., and Lamond, A.I. 2001. Dynamic targeting of protein phosphatase 1 within the nuclei of living mammalian cells. J. Cell Sci. 114: 4219-4228.

Trinkle-Mulcahy, L., Andrews, P.D., Wickramasinghe, S., Sleeman, J., Prescott, A., Lam, Y.W., Lyon, C., Swedlow, J.R., and Lamond, A.I.

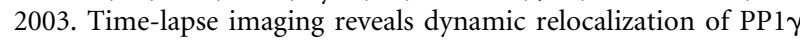
throughout the mammalian cell cycle. Mol. Biol. Cell 14: 107-117.

Tronchere, H., Wang, J., and Fu, X.D. 1997. A protein related to splicing factor U2AF35 that interacts with U2AF65 and SR proteins in splicing of pre-mRNA. Nature 388: 397-400.

Valcarcel, J., Gaur, R.K., Singh, R., and Green, M.R. 1996. Interaction of U2AF65 RS region with pre-mRNA branch point and promotion of base pairing with U2 snRNA [corrected]. Science 273: $1706-1709$.

Wang, Z., Hoffmann, H.M., and Grabowski, P.J. 1995. Intrinsic U2AF binding is modulated by exon enhancer signals in parallel with changes in splicing activity. RNA 1: 21-35.

Will, C.L. and Luhrmann, R. 1997. Protein functions in pre-mRNA splicing. Curr. Opin. Cell Biol. 9: 320-328.

Wouters, F.S., Verveer, P.J., and Bastiaens, P.I. 2001. Imaging biochemistry inside cells. Trends Cell Biol. 11: 203-211.

$\mathrm{Wu}$, J.Y. and Maniatis, T. 1993. Specific interactions between proteins implicated in splice site selection and regulated alternative splicing. Cell 75: 1061-1070.

Wu, J. and Manley, J.L. 1989. Mammalian pre-mRNA branch site selection by U2 snRNP involves base pairing. Genes \& Dev. 3: 1553-1561.

Wu, S., Romfo, C.M., Nilsen, T.W., and Green, M.R. 1999. Functional recognition of the $3^{\prime}$ splice site AG by the splicing factor U2AF35. Nature 402: 832-835.

Zamore, P.D. and Green, M.R. 1989. Identification, purification, and biochemical characterization of U2 small nuclear ribonucleoprotein auxiliary factor. Proc. Natl. Acad. Sci. 86: 9243-9247.

Zamore, P.D., Patton, J.G., and Green, M.R. 1992. Cloning and domain structure of the mammalian splicing factor U2AF. Nature 355: 609-614.

Zhang, D. and Rosbash, M. 1999. Identification of eight proteins that cross-link to pre-mRNA in the yeast commitment complex. Genes \& Dev. 13: $581-592$.

Zhang, M., Zamore, P.D., Carmo-Fonseca, M., Lamond, A.I., and Green, M.R. 1992. Cloning and intracellular localization of the U2 small nuclear ribonucleoprotein auxiliary factor small subunit. Proc. Natl. Acad. Sci. 89: 8769-8773.

Zhang, G., Taneja, K.L., Singer, R.H., and Green, M.R. 1994. Localization of pre-mRNA splicing in mammalian nuclei. Nature 372: 809-812. 


\section{Chusainow et al.}

Zhang, D., Abovich, N., and Rosbash, M. 2001. A biochemical function for the Sm complex. Mol. Cell 7: 319-329.

Zhou, Z., Licklider, L.J., Gygi, S.P., and Reed, R. 2002. Comprehensive proteomic analysis of the human spliceosome. Nature 419: 182-185.

Zhuang, Y. and Weiner, A.M. 1986. A compensatory base change in U1 snRNA suppresses a $5^{\prime}$ splice site mutation. Cell 46: 827-835.
Zhuang, Y.A., Goldstein, A.M., and Weiner, A.M. 1989. UACUAAC is the preferred branch site for mammalian mRNA splicing. Proc. Natl. Acad. Sci. 86: 2752-2756.

Zorio, D.A. and Blumenthal, T. 1999. Both subunits of U2AF recognize the $3^{\prime}$ splice site in Caenorhabditis elegans. Nature 402: 835-838.

Zuo, P. and Maniatis, T. 1996. The splicing factor U2AF35 mediates critical protein-protein interactions in constitutive and enhancerdependent splicing. Genes \& Dev. 10: 1356-1368. 

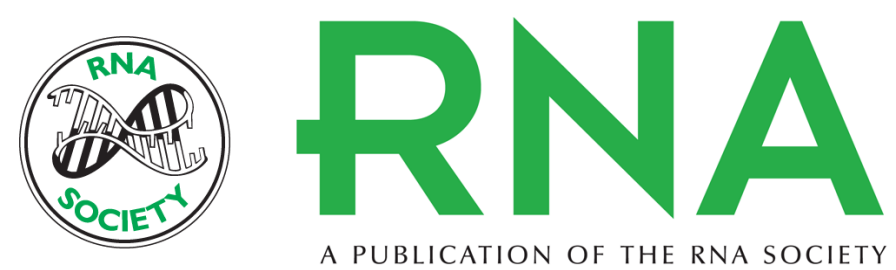

\section{FRET analyses of the U2AF complex localize the U2AF35/U2AF65 interaction in vivo and reveal a novel self-interaction of U2AF35}

JANET CHUSAINOW, PAUL M. AJUH, LAURA TRINKLE-MULCAHY, et al.

RNA 2005 11: 1201-1214

References This article cites 79 articles, 37 of which can be accessed free at:

http://rnajournal.cshlp.org/content/11/8/1201.full.html\#ref-list-1

License

Email Alerting Receive free email alerts when new articles cite this article - sign up in the box at the Service top right corner of the article or click here.

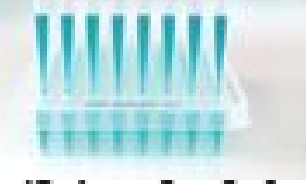

Providing Precise Solutions for your research.

To subscribe to RNA go to:

http://rnajournal.cshlp.org/subscriptions 